\title{
Replication Study of Association between Forkhead Box O3 (FOXO3) Polymorphisms and Tuberculosis in Korean Population
}

\author{
Sangjung Park ${ }^{1, *}$, Sung-Soo Kim ${ }^{1, * *}$, Hyun-Seok Jin ${ }^{1, *}$ and Jang-Eun Cho ${ }^{2, ;, *}$ \\ ${ }^{1}$ Department of Biomedical Laboratory Science, College of Life and Health Sciences, \\ Hoseo University, Asan, Chungnam 31499, Korea \\ ${ }^{2}$ Department of Biomedical Laboratory Science, Daegu Health College, Daegu 41453, Korea
}

\begin{abstract}
Tuberculosis (TB) remains a major health problem worldwide. TB depends not only on the characteristics of the Mycobacterium tuberculosis (MTB) but also on the genetic susceptibility of infected patients. Recent studies have suggested that $F O X O 3$ play an important role in the human immune associated disorder, such as TB. It was previously reported that $F O X O 3$ genetic variants associated with a risk of TB in Chinese population. In this study, we confirm whether the genetic polymorphism of the $\mathrm{FOXO3}$ gene, which was previously in Chinese, is reproduced in Korean population. Of the 154 SNPs were extracted from the FOXO3 gene, reproducibility analysis of the four SNPs performed in the previous study showed that there was a statistically significant correlation in the three SNPs (rs4946935, rs1536057, rs3800228). This study suggests that polymorphism of the FOXO3 gene in Koreans may affect the onset of tuberculosis and could be used to treat and prevent tuberculosis.
\end{abstract}

Key Words: Tuberculosis, Mycobacterium tuberculosis, FOXO3, SNPs

결핵은 결핵균(Mycobacterium tuberculosis, MTB)감염에 의해 발병하는 만성 감염 질환으로 매년 200 만 명의 사람 들이 사망하는 전 세계의 주요 질병 중 하나이다 $(\mathrm{KCDC}$, 2015). 결핵은 주로 MTB에 의해 호흡기를 통한 감염으로 전염되며 결핵균에 감염된 사람 중 대부분은 증상이 없 는 잠복 감염이며, 일부는 임상 증상을 보이는 활동성결 핵으로 진행된다(Petruccioli et al., 2016). 결핵의 발병은 $\mathrm{MTB}$ 의 특성뿐만 아니라 감염된 환자의 유전적 감수성 차이에 의해 일어날 수도 있다(Comstock, 1978). 결핵의 발병률이 매년 증가하는 경향을 나타내기 때문에 결핵에 대한 숙주 방어 체계와 관련된 유전자에 대해 규명할 필 요성이 높아지고 있다. 이에 따라 사람의 면역학적인 유 전적 차이가 결핵 발병에 영향을 줄 수 있다는 연구가 국내외에서 진행되고 있는 실정이다(Mahasirimongkol et al.,
2012; Jin and Park, 2017; Jin et al., 2019).

기존의 게놈 관련 연구에서 $\mathrm{FOXO3}$ 유전자 변이가 크 론병과 말라리아와 같은 자가면역 질환과 감염성 질환 의 중증도와 연관되어 있는 것으로 나타났다(Lee et al., 2013; Marlow et al., 2015). FOXO3는 주로 인슐린/IGF-1 신 호전달경로의 하위 표적으로 확인된 전사 인자로 세포주 기조절, 산화 및 세포자멸사에 저항하는 전사 인자이며, Forkhead 계열에 속한다(Brunet et al., 1999; Ticchioni et al., 2007; Arden 2008).

최근 연구에 따르면 $\mathrm{FOXO3}$ 는 결핵과 같은 면역 관련 감염 질환의 위험에 중요한 역할을 한다고 보고되고 있 다(Haoues et al., 2014; Lu et al., 2016). FOXO3는 결핵균 감 염 시 보호면역반응에서 신호전달 허브 역할을 한다. 특 히 사람의 대식세포에서 결핵균 감염에 의한 세포자멸사

Received: March 2, 2020 / Revised: March 26, 2020 / Accepted: March 26, 2020

* Professor, ${ }^{* *}$ Graduate student.

†Corresponding author: Jang-Eun Cho. Department of Biomedical Laboratory Science, Daegu Health College, 15 Yeongsong-ro, Buk-gu, Daegu 41453, Korea. Tel: +82-10-2456-8856, Fax: +82-53-320-1450, e-mail: jecho@dhc.ac.kr

(C) The Korean Society for Biomedical Laboratory Sciences. All rights reserved.

(C) This is an Open Access article distributed under the terms of the Creative Commons Attribution Non-Commercial License (http://creativecommons.org/licenses/by-nc/3.0/) which permits unrestricted non-commercial use, distribution, and reproduction in any medium, provided the original work is properly cited. 
Table 1. Associations between the 4 SNPs in the $\mathrm{FOXO} 3$ gene and tuberculosis in KARE subjects

\begin{tabular}{|c|c|c|c|c|c|c|c|}
\hline \multirow[b]{2}{*}{ No. } & \multirow[b]{2}{*}{ SNP } & \multirow[b]{2}{*}{ BP } & \multirow{2}{*}{$\begin{array}{l}\text { Minor } \\
\text { allele }\end{array}$} & \multicolumn{2}{|c|}{ MAF } & \multirow{2}{*}{$\begin{array}{c}\text { OR } \\
(95 \% \mathrm{CI})\end{array}$} & \multirow[b]{2}{*}{$P$-value } \\
\hline & & & & $\begin{array}{c}\text { Cases } \\
(\mathrm{n}=443)\end{array}$ & $\begin{array}{c}\text { Controls } \\
(\mathrm{n}=3,228)\end{array}$ & & \\
\hline 1 & rs1536057 & 108885623 & $\mathrm{~T}$ & 0.190 & 0.160 & $1.23(1.03 \sim 1.48)$ & 0.024 \\
\hline 2 & rs 12212067 & 108981196 & $\mathrm{G}$ & 0.133 & 0.115 & $1.20(0.97 \sim 1.47)$ & 0.093 \\
\hline 3 & rs3800229 & 108996963 & G & 0.248 & 0.215 & $1.21(1.03 \sim 1.43)$ & 0.019 \\
\hline 4 & rs4946935 & 109000742 & A & 0.248 & 0.214 & $1.22(1.03 \sim 1.44)$ & 0.017 \\
\hline
\end{tabular}

Abbreviations: BP, base pair; MAF, minor allele frequency; OR, odds ratio; SNP, single nucleotide polymorphism. The SNP positions are based on the NCBI Build 37 human genome assembly

는 $F O X O 3$ 전사 인자의 활성을 증가시키고, $\mathrm{PI} 3 \mathrm{~K} / \mathrm{Akt} /$ $F O X O 3$ 의 신호전달을 통해 IL-10 발현을 조절하여 면역 반응을 유도한다고 보고되었다(Haoues et al., 2014; Bouzeyen et al., 2019).

2019년에 중국인을 대상으로 FOXO3 유전자의 유전적 다형성이 결핵 발병에 영향을 미칠 수 있다는 연구가 보 고된 바 있다. 그 연구에서는 4 개의 $\mathrm{SNP}$ 의 차이가 결핵 발병에 영향을 미친다고 보고하였다(Wang et al., 2019). 그 러나 국내에서는 사람의 유전적 다형성에 의한 결핵 발 병의 연구가 많이 진행되지 않고 있는 실정이다. 따라서 이번 연구는 한국인 유전체 역학 조사 사업의 일환으로 구성되어 있는 코호트 자료를 활용하여 결핵이 발병했던 환자군과 건강 대조군을 분류하고, 두 그룹간의 $\mathrm{FOXO3}$ 유전자의 유전적 다형성(genetic polymorphism)이 결핵 발 병에 영향을 주었는지 확인하고자 유전적 변이에 대한 관 련성 연구(association study)를 시행하였다.

이번 연구에서 활용한 연구 대상자는 한국인 유전체 역 학 조사 사업(Korean Genome and Epidemiology Study; KoGES)의 일환인 Korean Association Resource (KARE)를 기반으로 하였고, 이 데이터는 질병관리본부 인체자원은 행에서 분양 받아 사용하였다(Cho et al., 2009) (KBN-2017038). 연구 대상자의 선별은 이전 연구와 동일하게 설정 하였으며(Jin and Park, 2017) 결핵 환자군은 이전에 결핵 진단을 받은 적이 있는 443 명, 건강 대조군은 특별한 질 환이 없는 3,228 명으로 선정하였다. 결핵 환자군과 건강 대조군간의 평균 나이는 각각 51.0 세, 51.6세로 통계적으 로 유의한 차이는 없었다(Table 1). 환자군과 대조군의 유 전 정보는 질병관리본부 $(\mathrm{KNIH})$ 와 호서대학교에서 연구 윤리 승인을 받은 후 결과 분석에 이용하였다(1041231170418-HR-056-02).

유전자 영역의 확장된 영역을 분석하기 위해 KARE 유
전형 자료를 바탕으로 $F O X O 3$ 유전자 영역에서 $\mathrm{MACH}$ 프로그램(version 1.016) (Li et al., 2010)을 이용하여 imputation SNP를 추가적으로 추출하였다. FOXO3 유전자 영역에 서 imputation은 HapMap database에서 중국인(Han Chinese Beijing)과 일본인(Japanese in Tokyo)의 것을 참고하여 진 행하였고, imputed SNP들 중에서 minor allele frequency (MAF)가 $1 \%$ 미만이거나 상관계수 $\left(r^{2}\right)$ 가 0.5 미만인 것은 분석에서 제외하였다. 각 $\mathrm{SNP}$ 의 염색체 내 위치는 UCSC Genome Browser on Human Feb. 2009 (GRCh37/hg19)를 기준 으로 결정하였다. 이렇게 $F O X O 3$ 유전자 영역에서 154개 의 SNP를 추출하였고, 이 중에서 앞선 연구 결과(Wang et al., 2019)에서 분석한 4개의 SNP에 대하여 결핵과 상관 관계가 있는지 확인해 보았다. 대부분의 통계 분석에는 PLINK version 1.07 (http://pngu.mgh.harvard.edu/ purcell/ plink)과 PASW Statistics version 21.0 (SPSS Inc. Chicago, IL, USA)을 사용하였다. 결핵 환자군과 건강 대조군에 대한 유전적 변이의 상관성 분석은 additive genetic model을 기 반으로 로지스틱 회귀 분석을 하였다. 이 분석을 수행할 때 나이, 지역, 성별을 공변수로 처리하였다. 분석 결과에 대한 유의 수준은 0.05 미만을 기준으로 하였다. 또한 분 석한 유전 정보를 바탕으로 Haploview version 4.2 (Whitehead Institute for Biomedical Research, Cambridge, MA, USA) 프로그램을 사용하여 연관불균형(linkage disequilibrium)을 확인하였다.

$F O X O 3$ 유전자에서 추출한 154 개의 $\mathrm{SNP}$ 중에서 이전 연구에서 수행한 4 개의 SNP에 대한 재현성 분석을 수행 한 결과 3 개의 $\mathrm{SNP}$ 에서 통계적으로 유의한 상관관계 $(P<$ 0.05 )가 있는 것을 확인하였다(Table 1). 이 중에서 가장 높 은 유의 수준을 보이는 SNP은 rs4946935 $(P=0.017)$ 이었고, 상대적 위험도(Odds ratio)는 1.22, 신뢰구간 $(95 \%$ Confidence interval)은 1.03 1.44를 나타냈다. rs4946935의 MAF는 건 


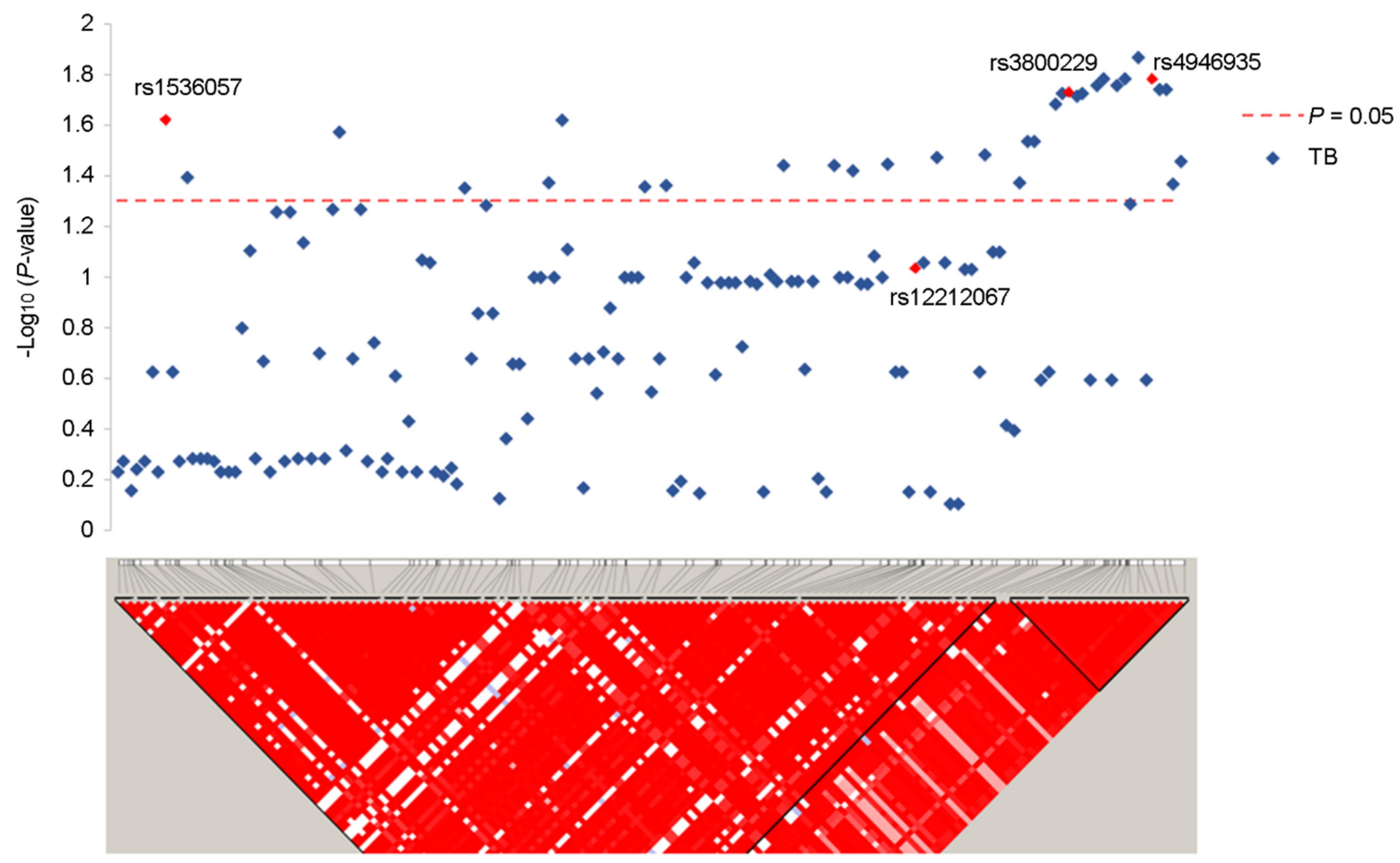

Fig. 1. The plot of $P$-values of the studied 154 SNPs, the gene structure and linkage disequilibrium blocks in the FOXO3 gene. The top panel shows the plots of $P$-values of the studied 154 SNPs in the FOXO3 gene in the logistic case-control analysis of the KARE data. Standard significant $P$-value threshold $(P=0.05)$ are indicated by the dotted lines. The four SNPs studied in this study were in red, and their rs number were described. The bottom panel shows a Haploview of LD $\left(r^{2}\right)$ based on genotyping data from 8,840 KARE data and are generated by using Haploview program.

강 대조군에서 $21.4 \%$, 결핵 환자군에서는 $24.8 \%$ 로 $3.4 \%$ 의 빈도 차이를 확인하였다. 따라서 $\mathrm{A}$ 염기를 보유할 경 우에 결핵에 대한 상대적 위험도가 높아지는 것을 알 수 있다. 유의 수준을 통과한 2개의 SNP도 minor allele를 보 유할수록 결핵에 대한 상대적 위험도가 높아지는 것을 확인하였다. 또한 $\mathrm{FOXO}$ 의 154 개의 $\mathrm{SNP}$ 에 대한 $\mathrm{LD}$ 블 록 구조를 확인했을 때, rs12212067과 rs1536057가 하나의 블록 구조를 구성하였고, rs4946935와 rs3800229가 또 다 른 블록 구조를 구성하였다(Fig. 1). 이를 통하여 rs1536057 과 rs122212067이 동반하여 연관성이 높은 SNP임을 알 수 있었고, 독립된 두 $\mathrm{LD}$ 블록에서 각각 통계적으로 유 의한 $\mathrm{SNP}$ 들이 존재함으로서 $\mathrm{FOXO}$ 의 유전적 다형성이 결핵 발병에 영향이 있을 수 있음을 알 수 있었다.

세포사멸, 세포증식, 염증 및 선천 면역에 관련된 여러 유전자의 발현을 조절하는 $F O X O 3$ 는 IL-10을 포함한 항 염증성 사이토카인의 조절을 통해 말라리아 감염을 증가 시킨다고 보고된 바 있다(Langhorne et al., 2004; Junqueira et al., 2010; Hwang et al., 2011; Lee et al., 2013). 앞서 말했듯
이 $F O X O 3$ 의 전사 인자 조절이 결핵균에 감염된 대식세 포의 IL-10의 작용을 조절하여 결핵 발병에 영향을 주고 (Bouzeyen et al., 2019), 활동성 결핵 환자에서 microRNA223은 상향조절되어 $F O X O 3$ 를 억제하여 대식세포의 세포 자멸사에 영향을 준다고 알려져 있다(Xi et al., 2015). 또한 $F O X O 3$ 다형성의 돌연변이는 전사 인자의 활성을 변화시 키고 결핵에 대한 감수성을 증가시킨다고 보고되었다 $(\mathrm{Lu}$ et al., 2016). 이렇듯 FOXO3의 유전적 다형성은 선천 면역 체계에서 결핵 발병을 조절할 수 있는 기작에 관여함으 로써 결핵균 감염에 대한 개개인의 발병에 대한 차이를 만들 수 있어 결핵 발병에 있어서 $F O X O 3$ 의 역할이 매우 중요하다고 생각된다.

이번 연구는 기존에 중국인을 대상으로 수행하였던 $\mathrm{FOXO} 3$ 유전자의 유전적 다형성이 한국인 코호트에서 도 동일하게 재현되는지 확인하고자 하였다. 결론적으로 $\mathrm{FOXO} 3$ 유전자의 154 개의 SNP 중에서 3개 SNP인 rs$4946935, \mathrm{rs} 1536057, \mathrm{rs} 3800229$ 가 상대적으로 유의한 결과 를 보였다. Wang이 보고하였던 중국인에서와 같이 한국 
인에서도 $\mathrm{FOXO3}$ 유전자의 유전적 다형성이 재현되고 있 음을 확인하였다. 즉 한국인 대상으로 상관관계가 있는 $\mathrm{FOXO3}$ 유전자의 $\mathrm{SNP}$ 의 다형성은 전사 인자 활성에 영 항을 주고, 이를 활용하여 결핵의 치료 및 예방에 활용할 수 있을 것으로 생각된다. 또한 $\mathrm{FOXO3}$ 와 결핵과의 연관 성에 대한 $\mathrm{SNP}$ 변이 및 분자 메커니즘에 대한 추가적인 연구가 더 필요할 것으로 생각된다.

\section{ACKNOWLEDGEMENT}

This research was supported by Basic Science Research Program through the National Research Foundation of Korea (NRF), funded by Ministry of Sciences, ICT \& Future Planning (2017R1C1B5016589). This study was conducted with bioresources from National Biobank of Korea, the Centers for Disease Control and Prevent ion, Republic of Korea (KBN2017-038).

\section{CONFLICT OF INTEREST}

The authors declare no conflict of interest.

\section{REFERENCES}

Arden KC. FOXO animal models reveal a variety of diverse roles for FOXO transcription factors. Oncogene. 2008. 27: 2345 -2350 .

Bouzeyen R, Haoues M, Barbouche MR, Singh R, Essafi M. FOXO3 transcription factor regulates IL-10 expression in Mycobacteria-infected macrophages, tuning their polarization and the subsequent adaptive immune response. Frontiers in Immunology. 2019. 10: 2922.

Brunet A, Bonni A, Zigmond MJ, Lin MZ, Juo P, Hu LS, Anderson MJ, Arden KC, Blenis J, Greenberg ME. Akt promotes cell survival by phosphorylating and inhibiting a forkhead transcription factor. Cell. 1999. 96: 857-868.

Cho YS, Go MJ, Kim YJ, Heo JY, Oh JH, Ban HJ, Yoon D, Lee MH, Kim DJ, Park M, Cha SH, Kim JW, Han BG, Min H, Ahn Y, Park MS, Han HR, Jang HY, Cho EY, Lee JE, Cho NH, Shin C, Park T, Park JW, Lee JK, Cardon L, Clarke G, McCarthy MI, Lee JY, Lee JK, Oh B, Kim HL. A large-scale genome-wide association study of Asian populations uncovers genetic factors influencing eight quantitative traits. Nature Genetics. 2009. 41:527-534.

Comstock GW. Tuberculosis in twins: a re-analysis of the Prophit survey. The American Review of Respiratory Disease. 1978. 117: 621-624.

Haoues M, Refai A, Mallasvialle A, Barbouche MR, Laabidi N, Deckert M, Essafi M. Forkhead box O3 (FOXO3) transcription factor mediated apoptosis in BCG-infected macrophages. Cellular Microbiology. 2014. 16: 1378-1390.

Hwang JW, Rajendrasozhan S, Yao H, Chung S, Sundar IK, Huyck HI, Pryhuber GS, Kinnula VL, Rahman I. FOXO3 deficiency leads to increased susceptibility to cigarette smoke-induced inflammation, airspace enlargement, and chronic obstructive pulmonary disease. J Immunol. 2011. 187: 987-998.

Jin HS, Park S. Association of the CD226 Genetic polymorphisms with Risk of Tuberculosis. Biomedical Science Letters. 2017. 23: 89-95.

Jin HS, Cho JE, Park S. Association between CD53 genetic polymorphisms and tuberculosis cases. Genes \& Genomics. 2019. 41: 389-395.

Junqueira C, Caetano B, Bartholemeu DC, Melo MB. Ropert C, Rodrigues MM, Gazzinelli RT. The endless race between Trypanosoma cruzi and host immunity: lessons for and beyond Chagas disease. Expert Reviews in Molecular Medicine. 2010. 15: 12: e29.

KCDC. Korean Tuberculosis Report. 2015. http://tbzero.cdc.go.kr/ tbzero/main.do?pageEvent $=\mathrm{N}$

Langhorne J, Albano FR, Hensmann M, Sanni L, Cadman E, Voisine C, Sponaas AM. Dendritic cells, pro-inflammatory responses, and antigen presentation in a rodent malaria infection. Immonological Reviews. 2004. 201: 35-47.

Lee JC, Espéli M, Anderson CA, Linterman MA, Pocock JM, Williams NJ, Roberts R, Viatte S, Fu B, Peshu N, Hien TT, Phu NH, Wesley E, Edwards C, Ahmad T, Mansfield JC, Gearry R, Dunstan S, Williams TN, Barton A, Vinuesa CG, UK IBD Genetics Consortium, Parkes M, Lyons PA, Smith KG. Human SNP links differential outcomes in inflammatory and infectious disease to a $\mathrm{FOXO3}$ regulated pathway. Cell. 2013. 155: 57-69.

Li Y, Willer CJ, Ding J, Scheet P, Abecasis GR, MaCH: using sequence and genotype data to estimate haplotypes and unobserved genotypes. Genet Epidemiol. 2010. 34:816-834.

Lu Y, Zhu Y, Wang X, Wang F, Peng J, Hou H, Sun Z. FOXO3 rs12212067: $\mathrm{T}>\mathrm{G}$ association with active tuberculosis in Han Chinese population. Inflammation. 2016. 39: 10-15. https:// doi.org/10.1007/s10753-015-0217-y

Mahasirimongkol S, Yanai H, Mushiroda T, Promphittayarat W, Wattanapokayakit S, Phromjai J, Yuliwulandari R, Wichukchinda 
N, Yowang A, Yamada N, Kantipong P, Takahashi A, Kubo M, Sawanpanyalert P, Kamatani N, Nakamura Y, Tokunaga K. Genome-wide association studies of tuberculosis in Asians identify distinct at-risk locus for young tuberculosis. Journal of Human Genetics. 2012. 57: 363-367.

Marlow G, Han DY, Triggs CM, Ferguson LR. Food intolerance: Associations with the rs12212067 polymorphism of FOXO3 in Crohn's disease patients in New Zealand. Journal of Nutrigenetics and Nutrigenomics. 2015. 8: 70-80.

Petruccioli E, Scriba TJ, Petrone L, Hatherill M, Cirillo DM, Joosten SA, Ottenhoff TH, Denkinger CM, Goletti D. Correlates of tuberculosis risk: predictive biomarkers for progression to active tuberculosis. The European Respiratory Journal. 2016. 48: 1751-1763.

Ticchioni M, Essafi M, Jeandel PY, Davi F, Cauusto JP, Deckert M, Bernard A. Homeostatic chemokines increase survival of B-chronic lymphocytic leukemia cells through inactivation of transcription factor FOХO3a. Oncogene. 2007. 26: 7081 $-7091$

Wang B, Wang Y, Wang L, He X, He Y, Bai M, Zhu L, Zheng J, Yuan D, Jin T. The role of FOXO3 polymorphisms in susceptibility to tuberculosis in a Chinese population. Molecular Genetics \& Genomic Medicine. 2019. 7: e770.

Xi X, Zhang C, Han W, Zhao H, Zhang H, Jiao J. MicroRNA-223 is upregulated in active tubercuclosis patients and inhibits apoptosis of macrophages by targeting $\mathrm{FOXO3}$. Genet Test Mol Biomarkers. 2015. 19: 650-656.

https://doi.org/10.15616/BSL.2020.26.1.42

Cite this article as: Park S, Kim SS, Jin HS, Cho JE. Replication Study of Association between Forkhead Box O3 (FOXO3) Polymorphisms and Tuberculosis in Korean Population. Biomedical Science Letters. 2020. 26: 42-46. 